\title{
Gender differences in barriers to alcohol and other drug treatment in Cape Town, South Africa
}

\author{
B Myers',2, J Louw ${ }^{3}$, S Pasche ${ }^{1}$ \\ ${ }^{1}$ Alcohol and Drug Abuse Research Unit, South African Medical Research Council, Tygerberg, South Africa \\ 2Department of Psychiatry and Mental Health, University of Cape Town, Cape Town, South Africa \\ ${ }^{3}$ Department of Psychology, University of Cape Town, Cape Town, South Africa
}

\begin{abstract}
Objective: The study aimed to identify gender differences in barriers to alcohol and other drug (AOD) treatment use among disadvantaged communities in Cape Town, South Africa. The Behavioral Model of Health Services Utilization was used as an analytic framework. Method: A case-control design was used to compare 434 individuals with AOD problems from disadvantaged communities who had accessed treatment with 555 controls who had not accessed treatment on a range of variables. Logistic regression procedures were employed to examine the unique profile of variables associated with treatment utilization for male and female participants. Results: Few gender differences emerged in terms of the pattern of variables associated with AOD treatment use. Greater awareness of treatment options and fewer geographic access and affordability barriers were strongly associated with an increased likelihood of AOD treatment use for both men and women from disadvantaged communities. However, while similar types of barriers to treatment were reported by men and women, these barriers had a greater impact on treatment utilization for women compared to men. Conclusion: Compared to men, women from disadvantaged communities in South Africa do not have equal access to AOD treatment. Recommendations on how to reduce these barriers and ways to improve AOD treatment use among women from disadvantaged communities in South Africa are provided.
\end{abstract}

Keywords: Health care quality; Access and evaluation; Gender; Substance abuse treatment centres; South Africa

Received: 01-03-2010

Accepted: 10-06-2010

doi: $10.4314 / a j p s y . v 14 i 2.7$

\section{Introduction}

Findings from national epidemiological research point to high rates of untreated alcohol and other drug (AOD) use disorders in South Africa. ${ }^{1,2}$ The high prevalence of untreated AOD problems is also apparent from the large burden these problems place on South African health care and legal system. ${ }^{3,4}$ Compared to the other provinces in the country, the Western Cape has significantly higher rates of AOD problems. ${ }^{1}$ Cape Town, the capital of the Western Cape is particularly afflicted, with the highest proportion of alcohol and drug positive arrestees ${ }^{3}$ and emergency room patients compared to other major cities in the country. ${ }^{4}$ Taken together, these findings highlight the need for accessible AOD treatment services in Cape Town.

Despite the demand for and documented benefits of AOD treatment, access to treatment is limited in South Africa. ${ }^{5}$ While the limited availability of AOD services restricts access to treatment for all South Africans, treatment seems relatively more difficult to access for people from Black/African and Coloured ${ }^{\text {la }}$ communities disadvantaged during the course of apartheid. ${ }^{6}$ Treatment is also relatively more difficult for women to access than men, with women comprising roughly a quarter of the treatment population. ${ }^{7}$ Women from disadvantaged communities are particularly

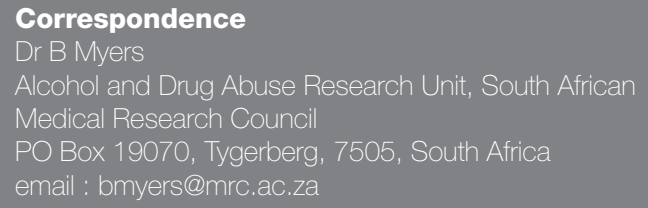


underrepresented in AOD treatment, accounting for only a small proportion of the total population of women in treatment While there is limited data on AOD treatment need among women from disadvantaged communities, the high prevalence of foetal alcohol syndrome in disadvantaged communities in the Western $\mathrm{Cape}^{8}$ and high levels of AOD abuse among Black/African and Coloured women in Cape Town ${ }^{9}$ suggest that women from these communities have many unmet treatment needs.

In order to improve AOD treatment utilization among women from disadvantaged communities, it is important to identify the unique profile of factors associated with AOD treatment initiation so that any gendered barriers to treatment utilization can be addressed. Studies conducted in the USA have identified several barriers to AOD treatment utilization that are specific to women (including childcare needs, the fear of losing child custody, a lack of information about how to get into treatment, concurrent mental health difficulties, economic barriers, being a victim of physical or sexual abuse, and stigma). ${ }^{10-12}$ However, the extent to which these findings are applicable to the South African context is unknown. This is largely because AOD treatment services research in South Africa has not compared recipients of services with community-based samples of untreated persons. This has made it difficult to identify factors that facilitate or restrict $A O D$ treatment utilization for men and women from disadvantaged communities and has hampered the development of interventions to improve utilization. This study hopes to redress this gap by exploring differences in the pattern of predictors for AOD treatment utilization among men and women. More specifically, the study aimed to identify gender differences on the profile of variables associated with treatment utilization (and non-utilization) for persons from disadvantaged communities in Cape Town, South Africa.

The theoretical basis for this study was the Behavioral Model of Health Services Utilization (BHSU). ${ }^{13}$ The BHSU is widely used to examine health services use, including AOD services. ${ }^{12-14}$ The BHSU suggests that health service use is partly a function of the separate and combined influence of predisposing factors, factors that enable or restrict health service use, and need variables. Predisposing characteristics, such as demographic and attitudinal-belief variables, exist within the individual prior to the onset of a particular health need and predispose a person to use services. Enabling factors represent the actual ability of an individual to obtain health services and include affordability factors (due to income and health insurance), geographic accessibility and awareness of services, as well as psychological and cognitive factors (such as psychological functioning). Finally, need variables reflect internal and external perceptions that illness levels are severe enough to require health services. ${ }^{13,15}$

\section{Method}

\section{Study design}

This study used a case-control design to compare cases and controls on a range of variables thought to be associated with the outcome of interest, namely AOD treatment utilization. This study defined cases as persons from disadvantaged communities with AOD problems who reported AOD treatment utilization in the 12 months preceding the study. Controls were defined as persons from disadvantaged communities who had not used AOD treatment prior to this study, despite having AOD problems that required treatment. To control for selection bias, frequency matching techniques were used to match cases and controls on gender and race dimensions. To limit recall bias, we used time-line follow back (TLFB) procedures to collect retrospective data. ${ }^{16}$

\section{Recruitment and data collection procedures}

From June 2006 through January 2007, convenience samples of men and women were recruited from AOD treatment programmes and communities using snowball sampling techniques. Cases ("treatment use") were identified at nonprofit AOD treatment facilities in the Cape Town metropole, which served as starting points for sampling. Counsellors from these facilities were trained to screen recipients of services for study eligibility. Of the 440 persons screened, all met the inclusion criteria. Having established eligibility, the counsellors obtained written informed consent from potential cases so that locator information could be gathered and passed on to the study's fieldworkers. Fieldworkers then contacted these recruits to obtain written informed consent to conduct an interview. Only six recruits refused to participate in the interview. This interview took approximately 90 minutes to complete during which time an Access to treatment interview questionnaire (ATQ) was administered in a face-to-face format.

Controls ("non-use") were recruited by a team of experienced fieldworkers. To ensure controls represented the population of persons with AOD problems in disadvantaged communities, subjects were recruited from a range of these communities. Two residential areas from each of the six substructures of the Cape Town metropole were selected as key focus areas for sampling. To be selected, the area had to consistently appear in the South African Community Epidemiology Network on Drug Use's list of top ten residential areas for AOD problems. Selected areas also had to be classified as a "Black" or "Coloured" residential area under the apartheid regime, have high levels of health and social problems, and be a low-income area. Fieldworkers entered these communities by contacting organisations, leaders, and individuals with known interests in the AOD field and asking them to identify potential recruits. Informants were assured that their anonymity would be protected. Informants were easily able to identify controls. This is partly due to the social structure of poorer South African communities where people live together in close confines and often depend on each other for survival. In such communities, keeping involvement in drug use private is difficult.

Fieldworkers then contacted potential controls (who served as starting points for snowball sampling) to obtain consent to screen them for study eligibility. These individuals did not seem offended about being asked to participate in the study and responses were mostly positive. The intervieweradministered screener took approximately five minutes to complete and collected information on area of residence, gender, age, race, and income in the last 30 days. Controls were also screened for current AOD problems to objectively assess their need for treatment. The Texas Christian University (TCU) Drug Screen was used for this purpose. ${ }^{17}$ For this screen, a composite score of 3 or greater indicates relatively severe drug-related problems that correspond to a DSM-IV-TR drug dependence diagnosis. ${ }^{18}$ All controls scored above this 
cut-off point, indicating an objective need for treatment. Of the 559 potential recruits screened, only four did not meet the study's eligibility criteria. An overall response rate of $98.3 \%$ was obtained. For eligible participants, fieldworkers obtained written consent to conduct a full interview. This interview took approximately 90 minutes to complete during which time the ATQ was administered. Fieldworkers provided participants with refreshments, feedback, and referrals to AOD services where requested.

Ethical approval for this study was granted by the Ethics Review Board of the Faculty of Humanities at the University of Cape Town.

\section{Participants}

To be selected for inclusion in the study, potential recruits had to be at least 18 years old, self-identify as Black/African or Coloured, earn less than ZAR2500 per month2a, have AOD problems (either treated or untreated), and provide informed consent to participate in the study. The final sample consisted of 434 cases and 555 controls $(\mathrm{N}=989)$. Of these controls, approximately 46 were selected from each recruitment area. Chi-square tests of association revealed that cases and controls did not differ by gender or race. Similarly, independent sample t tests showed that the mean age and level of education did not differ among cases and controls (Table I).

\section{Measures}

The Access to Treatment interview schedule (ATQ) was compiled to examine AOD treatment utilization among South African populations. The ATQ includes items that explore treatment use, treatment need, factors thought to predispose individuals to using treatment, and factors thought to enable or restrict treatment use.

\section{Use of $A O D$ treatment}

The criterion variable for this study was AOD treatment utilization. This was assessed by the question: "Have you ever received treatment for AOD problems? " This item had a "yes" (1) or a "no" (0) response.

\section{Need for treatment}

The questions: "Do you think you have an AOD problem?" and "Have other people suggested that you need help to change your use of AODs?" examined internally and externally perceived treatment need, respectively. These items had a "yes" (1) or "no" (0) response. The Stages of Change,

Readiness and Treatment Eagerness Scale (SOCRATES-8D) measured readiness to change AOD use; a situational indicator of perceived need. ${ }^{19}$ The SOCRATES consists of the problem recognition, ambivalence and the taking steps to change subscales for which this study obtained alpha coefficients ranging between .91 and .95.

\section{Predisposing factors}

Predisposing factors included the demographic variables of age and gender and the social-structural variables of race/ethnicity, education level, and neighbourhood disadvantage. Education level was based on the number of years of education received, treated as a continuous variable. The Neighbourhood Environment Scale (NES) measured neighbourhood disadvantage. ${ }^{20}$ For this study, the wording of the NES was adapted for an adult population. A Cronbach alpha coefficient of 82 was obtained for this scale.

\section{Enabling and restricting factors}

A 5-item "Affordability scale" was constructed to measure the extent to which treatment and transport costs hampered utilization. These items were taken from Miller and Tonigan's (1995) "Barriers questionnaire". ${ }^{21}$ Items are rated on a 5-point Likert scale and aggregated responses averaged to give a composite score, with higher scores indicating more cost barriers. A Cronbach alpha coefficient of .84 was obtained for this scale. Participants were also asked whether competing financial priorities (such as the need to pay for food) limited treatment use. Responses for this item were coded as "yes" (1) or "no" (0).

Awareness of AOD treatment services was examined through asking participants to list all known treatment services. The number of known AOD treatment facilities was then calculated, with larger numbers indicating greater awareness of services. In addition, the geographic accessibility of treatment was examined through asking participants to estimate the time it took (in 15 minute intervals) to travel to the nearest service.

Psychological functioning was examined through the use of TCU's depression and anxiety scales. For these scales, higher scores indicate greater levels of depression and anxiety.22 This study obtained Cronbach alpha coefficients ranging from .81 to .92 for these scales. The 10-item Stigma Consciousness Scale was used to examine internalized stigma related to participants' AOD use. ${ }^{23}$ This study obtained a Cronbach alpha coefficient of 84 for the scale.

2a. At the time of the study USD $1=Z$ ZAR 9

Table I: Demographic information for the overall sample ( $N=989$ )

\begin{tabular}{|l|l|l|l|l|}
\hline Variable & Cases & Control & Chi-square/ t -test (p) & Overall \\
\hline Male & $54.4 \%(236)$ & $50.3 \%(279)$ & $1.65(0.20)$ & $52.1 \%(515)$ \\
Female & $45.6 \%(198)$ & $49.7 \%(276)$ & & $47.9 \%(474)$ \\
Black/African & $50.9 \%(221)$ & $50.3 \%(279)$ & $0.04(0.84)$ & $50.6 \%(500)$ \\
Coloured & $49.1 \%(213)$ & $49.7 \%(276)$ & & $49.4 \%(489)$ \\
Mean age in years(SD) & $24.95(4.81)$ & $25.43(5.98)$ & $1.38(0.17)$ & $25.22(5.51)$ \\
Mean education - grade (SD) & $11.55(1.57)$ & $11.45(1.52)$ & $-0.95(0.34)$ & $11.50(1.54)$ \\
Total (N) & 434 & 555 & - & 989 \\
\hline
\end{tabular}


Abstinence-specific social support was examined via the TCU social support scale which measures the extent to which others act as external supports for treatment and abstinence. ${ }^{22}$ Higher composite scores indicate greater levels of support. This study obtained a Cronbach alpha coefficient of .77 for the scale.

A 10-item "Treatment concerns" scale was constructed to measure concerns about the AOD treatment process. Items were taken from Miller and Tonigan's (1995) "Barriers questionnaire". ${ }^{21}$ For this scale, items are aggregated to give a composite score and higher scores reflect more treatment concerns. A Cronbach alpha coefficient of .90 was obtained for this scale.

\section{Analysis procedures}

Bivariate comparisons of the utilization variable and the predisposing, enabling and need measures were conducted separately for each gender group. Chi-square tests of association were conducted on categorical variables by utilization and odds ratios were calculated to measure the strength of these associations. Independent sample t-tests were used to compare the utilization groups on continuous variables. The final step was to conduct logistic regression analyses to determine which predisposing, enabling and need factors independently predicted treatment utilization. Utilization was regressed separately for male and female participants so that the unique profile of variables associated with utilization for each gender could be identified. For each regression analysis, all predisposing, enabling and need variables significantly associated with utilization in bivariate analyses were entered into the model using a stepwise procedure.

\section{Results}

\section{Bivariate analyses}

Predisposing variables

For males, the NES was the only predisposing factor significantly associated with treatment use. Men who did not access treatment obtained higher scores on this scale compared with men who accessed treatment. This measure was not significantly associated with utilization for women. None of the other predisposing variables examined in this study were significantly associated with utilization (Table II).

\section{Need variables}

The categorical variable "others suggesting the need for AOD treatment" was significantly associated with utilization for both genders $\left(\chi^{2}(1, N=515)=21.34, p<0.001\right.$ for males; $\chi^{2}(1, N$ $=474)=36.75, \mathrm{p}<0.001$ for females $)$. The odds of utilizing treatment increased almost three-fold for male participants (OR = 2.92; CI (95): 1.83-4.66) and almost six-fold for female participants (OR =5.81; CI (95): 3.13-10.79) who had someone suggest that they needed help for their AOD problem. Significant differences also were found between cases and controls on the SOCRATES subscales. For both genders, the treatment use group reported higher scores on all three subscales than the treatment non-use group (Table II).

\section{Enabling/restricting variables}

The variable "competing financial priorities" was significantly associated with utilization for both genders $\left(\chi^{2}(1, N=515)\right.$ $=41.99, \mathrm{p}<0.001$ for males and $\chi^{2}(1, \mathrm{~N}=474)=36.75, \mathrm{p}<$ 0.001 for females). Men with no competing financial priorities had three-fold greater odds of accessing treatment than men with competing financial demands (OR = 3.23; CI (95): 2.27 -

\section{Table II: Independent sample $t$ tests for continuous predisposing, need and enabling variables by utilization for each gender group}

\begin{tabular}{|c|c|c|c|c|c|c|}
\hline \multirow[t]{2}{*}{ Variables } & \multicolumn{3}{|c|}{ Males } & \multicolumn{3}{|c|}{ Females } \\
\hline & $\begin{array}{l}\text { No use Controls } \\
(N=279) \\
\text { Mean }(S D)\end{array}$ & $\begin{array}{l}\text { Treatment use } \\
(N=236) \\
\text { Mean (SD) }\end{array}$ & t value (df) & $\begin{array}{l}\text { No use Controls } \\
\left(\begin{array}{l}N=276) \\
\text { Mean (SD) }\end{array}\right.\end{array}$ & $\begin{array}{l}\text { Treatment use } \\
\text { Cases }(N=198) \\
\text { Mean }(S D)\end{array}$ & t value (df) \\
\hline $\begin{array}{l}\text { Predisposing variables } \\
\text { Age } \\
\text { Education (years) } \\
\text { NES }\end{array}$ & $\begin{array}{l}25.80(5.78) \\
11.49(1.54) \\
42.16(3.23)\end{array}$ & \begin{tabular}{|l|}
$25.25(4.93)$ \\
$11.58(1.54)$ \\
$40.53(5.14)$
\end{tabular} & $\begin{array}{l}1.14(513) \\
-.69(498) \\
4.36(513)^{\star \star \star}\end{array}$ & \begin{tabular}{|l|}
$25.05(6.17)$ \\
$11.42(1.51)$ \\
$42.57(3.60)$
\end{tabular} & $\begin{array}{l}24.60(4.65) \\
11.51(1.60) \\
42.48(4.77)\end{array}$ & $\begin{array}{l}.87(472) \\
-.61(409) \\
0.21(472)\end{array}$ \\
\hline $\begin{array}{l}\text { Need for treatment variables } \\
\text { Socrates- Problem recognition } \\
\text { Socrates-Ambivalence } \\
\text { Socrates- Taking steps }\end{array}$ & $\begin{array}{l}30.94(8.22) \\
33.37(7.93) \\
33.7(5.40)\end{array}$ & $\begin{array}{l}36.77(5.95) \\
37.83(7.57) \\
34.30(6.39)\end{array}$ & $\begin{array}{l}-6.42(513)^{\star \star \star} \\
-5.48(513)^{\star \star \star} \\
-8.54(513)^{\star \star \star}\end{array}$ & \begin{tabular}{|l|}
$29.00(8.10)$ \\
$30.92(9.38)$ \\
$31.09(5.68)$
\end{tabular} & $\begin{array}{l}37.02(6.57) \\
37.57(7.79) \\
32.08(4.90)\end{array}$ & $\begin{array}{l}-10.04(472)^{\star \star \star} \\
-8.50(472)^{\star \star \star} \\
-18.96(472)^{\star \star \star}\end{array}$ \\
\hline $\begin{array}{l}\text { Enabling variables } \\
\text { Treatment concerns } \\
\text { Stigma consciousness } \\
\text { Abstinence support } \\
\text { Depression } \\
\text { Anxiety } \\
\text { Number of known treatment centres } \\
\text { Time to treatment } \\
\text { Affordability barriers }\end{array}$ & $\begin{array}{l}25.88(8.52) \\
7.73(1.48) \\
35.69(5.64) \\
33.12(6.65) \\
34.64(8.17) \\
2.03(0.82) \\
3.57(0.61) \\
38.72(27.60)\end{array}$ & \begin{tabular}{|l|}
$28.52(8.03)$ \\
$8.21(1.78)$ \\
$38.05(4.27)$ \\
$38.79(7.44)$ \\
$40.26(7.30)$ \\
$3.81(0.80)$ \\
$2.72(0.75)$ \\
$6.46(9.91)$
\end{tabular} & $\begin{array}{l}-3.61(507)^{\star \star \star} \\
-3.30(513)^{\star \star \star} \\
-5.26(513)^{\star \star \star} \\
-9.04(476)^{\star \star \star} \\
-8.17(513)^{\star \star \star} \\
-25.08(502)^{\star \star \star} \\
14.16(513)^{\star \star \star} \\
15.29(513)^{\star \star \star}\end{array}$ & \begin{tabular}{|l|}
$26.99(8.55)$ \\
$7.52(1.57)$ \\
$34.86(5.46)$ \\
$31.90(7.96)$ \\
$33.59(9.11)$ \\
$2.06(1.03)$ \\
$3.76(0.46)$ \\
$38.80(6.01)$
\end{tabular} & $\begin{array}{l}31.11(7.08) \\
9.04(1.31) \\
36.70(5.01) \\
37.91(8.40) \\
37.91(8.40) \\
3.99(0.86) \\
2.73(0.75) \\
28.27(8.89)\end{array}$ & $\begin{array}{l}-5.55(472)^{\star \star \star} \\
-11.16(472)^{\star \star \star} \\
-3.81(445)^{\star \star \star} \\
-7.68(414)^{\star \star \star} \\
-5.27(472)^{\star \star \star} \\
-21.48(472)^{\star \star \star} \\
18.52(472)^{\star \star \star} \\
15.38(472)^{\star \star \star}\end{array}$ \\
\hline
\end{tabular}


4.76). Similarly, women without competing financial priorities had almost six times greater odds of accessing treatment compared to women with competing demands ( $\mathrm{OR}=5.56$; CI (95): 3.71-8.33).

For both genders, cases obtained higher scores on the treatment concerns and stigma consciousness scales than controls. Cases also obtained significantly higher scores on the TCU abstinence support, depression, and anxiety scales than controls. For men and women, cases reported significantly shorter travelling times to the nearest treatment centre, fewer affordability barriers and greater awareness of treatment services than controls (Table II)

\section{Logistic regression of utilization}

Utilization was regressed separately for each gender while controlling for the potential confounding effect of race. A test of the full model versus the model with the intercept only was statistically significant for men $\left(\chi^{2}(9 ; N=519)=527.48, \mathrm{p}<\right.$ $.001)$ and women $\left(\chi^{2}(10 ; N=474)=556.23, \alpha<.001\right)$. These models accounted for approximately 86\% (Nagelkerke $\mathrm{R}^{2}=$ .857) and 93\% (Nagelkerke $\left.R^{2}=.929\right)$ of the estimated variance in utilization for men and women, respectively. According to the Hosmer and Lemeshow test, the models were a good fit for the data $\left(\chi^{2}(8 ; \mathrm{N}=515)=5.09, \mathrm{p}=.747\right.$ for men; $\chi^{2}(8 ; N=474)=.27, p=.998$ for women).

For men and women, few treatment need and predisposing variables were significantly associated with utilization after statistically adjusting for the other variables in the model. For men, NES was the only predisposing measure significantly (albeit weakly) associated with utilization. For every one unit increase in the scale (reflecting greater disadvantage), the odds of men not utilizing treatment increased by a multiplicative factor of 1.25. No predisposing variables were significantly associated with treatment utilization for women (Table III). For the need variables, the probability of utilization increased for men with greater levels of problem recognition and for women who were taking positive steps to change their AOD use. However, these aspects of readiness to change were weakly associated with utilization (Table III).

Several enabling variables were significantly and strongly associated with utilization for men and women. Awareness of services was positively associated with utilization. For every additional treatment centre that a man or woman knew of, the odds of utilizing treatment increased by a multiplicative factor of 5.85 and 7.09, respectively. Geographic accessibility was negatively associated with utilization. For every 15 minute increase in travelling time to treatment, the odds of not accessing treatment increased by a multiplicative factor of 9.09 for men and 11.10 for women. Affordability barriers and competing financial priorities also were significant partial predictors of utilization for both genders. Men and women without competing financial priorities had almost a 3 and 17 times greater likelihood of accessing treatment compared to their respective counterparts with competing financial priorities. In addition, every one-unit increase in the affordability barriers scale augmented the odds of not accessing treatment 1.30 times for women and 1.14 times for men. Barriers related to treatment concerns were associated with utilization for men and women, with every one unit increase in this scale increasing the odds of utilizing treatment by a multiplicative factor of 1.10 and 1.27, respectively. Finally, stigma consciousness was positively associated with utilization for women only. Every one-unit increase in this scale increased the odds of accessing treatment by a multiplicative factor of 3.14 (Table III).

\section{Table III: Summary of multiple logistic regression analyses using predisposing, enabling and need factors as predictors of substance abuse treatment utilization \# a}

\begin{tabular}{|c|c|c|c|c|c|c|c|c|}
\hline \multirow[t]{2}{*}{ Predictor Variables } & \multicolumn{4}{|c|}{ Male $(N=515)$} & \multicolumn{4}{|c|}{ Female $(N=474)$} \\
\hline & $b$ & SE & Wald (df) & OR (95\% Cl) & $b$ & SE & Wald (df) & OR (95\% Cl) \\
\hline $\begin{array}{l}\text { Predisposing variables } \\
\text { NES }\end{array}$ & -.23 & .06 & $16.80(1)^{\star \star \star}$ & $.80(.71-.89)$ & - & - & - & - \\
\hline $\begin{array}{l}\text { Need for treatment variables } \\
\text { Socrates problem recognition } \\
\text { Socrates taking steps }\end{array}$ & $\begin{array}{l}.10 \\
-.01\end{array}$ & $\begin{array}{l}.04 \\
.03\end{array}$ & $\begin{array}{l}6.09(1)^{*} \\
.05(1)\end{array}$ & $\begin{array}{l}1.11(1.02-1.20) \\
.99(.93-1.06)\end{array}$ & .23 & .05 & $17.57(1)^{\star \star \star}$ & $1.26(1.13-1.40)$ \\
\hline $\begin{array}{l}\text { Enabling/restricting variables } \\
\text { Awareness: } \\
\text { Number of known treatment centres } \\
\text { Geographic access: } \\
\text { Travelling time to treatment } \\
\text { Affordability: } \\
\text { No competing financial priorities } \\
\text { Affordability barriers } \\
\text { Treatment concerns } \\
\text { Stigma consciousness }\end{array}$ & $\begin{array}{l}1.77 \\
-2.23 \\
1.07 \\
-.13 \\
.06 \\
-\end{array}$ & $\begin{array}{l}.23 \\
.33 \\
.43 \\
.03 \\
.02 \\
-\end{array}$ & $\begin{array}{l}58.84(1)^{\star \star \star} \\
45.31(1)^{\star \star \star} \\
45.31(1)^{\star \star \star} \\
24.59(1)^{\star \star \star} \\
6.52(1)^{\star} \\
-\end{array}$ & $\begin{array}{l}5.85(3.72-9.18) \\
.11(.06-.21) \\
2.91(1.25-6.76) \\
.88(.84-.93) \\
1.06(1.01-1.11) \\
-\end{array}$ & $\begin{array}{l}1.93 \\
-2.40 \\
2.86 \\
-.25 \\
.24 \\
1.14\end{array}$ & $\begin{array}{l}.36 \\
.59 \\
.69 \\
.06 \\
.06 \\
.26\end{array}$ & $\begin{array}{l}20.62(1)^{\star \star \star} \\
14.99(1)^{\star \star \star} \\
16.74(1)^{\star \star \star} \\
18.54(1)^{\star \star \star} \\
16.46(1)^{\star \star \star} \\
19.58(1)^{\star \star \star}\end{array}$ & $\begin{array}{l}7.09(4.52-12.26) \\
.09(.03-.32) \\
17.39(4.43-68.32) \\
.78(.69-.87) \\
1.27(1.13-1.42) \\
3.14(1.89-5.20)\end{array}$ \\
\hline
\end{tabular}




\section{Discussion}

Our findings suggest that although men and women from disadvantaged communities in Cape Town share a core set of predictors for AOD treatment utilization, women from these communities appear more vulnerable to the effects of these barrier variables than their male counterparts.

More specifically, awareness of AOD treatment services is an important enabling resource for men and women from disadvantaged communities, with greater awareness increasing the likelihood of treatment utilization. However as the association between awareness and treatment utilization was stronger for women than for men, it seems that this predictor variable holds greater importance for women's use of treatment services than for men. The nature of women's social networks might help account for this finding. The role that significant others play in facilitating treatment use for women is well documented, with social networks supportive of treatment buffering against the effects of limited awareness. ${ }^{24}$ Partial support for this explanation is provided by the finding from bivariate analyses that women for whom significant others had suggested the need for treatment had double the odds of accessing treatment compared to their male counterparts. The significance of this variable suggests that interventions targeted at the level of the social network may be an effective strategy for improving awareness of and access to treatment, particularly for women. This possibility requires further investigation in a study that directly examines the impact of social networks on awareness of and use of treatment services.

In addition, our findings highlight the role that financial barriers play in limiting AOD treatment utilization for men and women from disadvantaged communities. Greater affordability concerns (related to treatment and transport costs) and the presence of competing financial priorities diminish the chances of AOD treatment utilization, even after controlling for the influence of predisposing and treatment need variables. While financial barriers limit treatment use for men and women, these barriers are stronger determinants of utilization for women from disadvantaged communities relative to their male counterparts. This suggests that women from these communities are more vulnerable to the effects of financial barriers than men. The saliency of financial concerns as a treatment barrier for women is not altogether surprising as women in South Africa have relatively lower incomes than men. ${ }^{25}$ In addition, like many other African countries, South Africa is still largely a patriarchal society in which men often control women's incomes. ${ }^{26}$ As a result, many women in South Africa may not have access to an independent income to pay for treatment.

The increased susceptibility of women to financial barriers may also account for the finding that geographic access barriers (such as lengthy travel times to treatment) disproportionately affect AOD treatment utilization for women from disadvantaged communities compared to men. Findings from previous studies suggest that financial barriers often compound geographic access barriers. ${ }^{27}$ For South African women with competing financial priorities and limited income, lengthy travel times may be unaffordable due to the costs associated with public transport as well as the potential loss of income associated with difficult and lengthy commutes. Regardless of the reasons for these gender differences, these findings are worrisome as they suggest that women from disadvantaged communities experience greater difficulty in accessing treatment than men. Service providers thus need to consider ways of reducing geographic access and financial barriers for people from disadvantaged communities in general and women from these communities in particular. One strategy for reducing these barriers would be to introduce mobile outpatient AOD services into these communities. Not only would such services improve treatment availability, but they would also reduce women's travel time to and the costs of AOD treatment. Another strategy for reducing financial and geographic access barriers would be to provide prospective female clients from disadvantaged communities with tokens for public transport or transport services.

Apart from these shared set of predictors, this study found a few variations in the profile of variables associated with AOD treatment utilization among men and women from disadvantaged communities. First, the SOCRATES problem recognition subscale, was significantly (albeit weakly) associated with access for men, but not for women. In contrast, the SOCRATES taking steps to change subscale was weakly associated with treatment utilization for women but not for men. These differences can be understood by examining the SOCRATES more closely. The SOCRATES scale measures three dimensions of readiness to change that correspond to different stages of change as conceptualised by the Transtheoretical Model of Behavioural Change. ${ }^{19}$ Compared to the "Taking steps" subscale which refers to an action stage, the problem recognition subscale relates to an earlier stage of change, the contemplation phase. Our findings therefore suggest that men are more likely to access treatment earlier on in their decision to change their drug use behaviours than women. Therefore, these differences probably reflect the greater difficulties that women experience in accessing treatment relative to their male counterparts.

In addition, perceived stigma played a positive role in women's use of AOD treatment, but was not associated with men's use of treatment services. This is surprising as it contradicts findings from earlier research in which the disproportionate degree to which stigma is experienced by female AOD users relative to men is thought to hinder rather than promote their entry into treatment. ${ }^{11}$ One possible explanation lies in this study's measurement of perceived stigma. This study employed the stigma consciousness scale which measures perceptions of being judged negatively on the basis of one's AOD use rather than on the basis of one's use of AOD treatment services. ${ }^{23}$ It is quite possible that high levels of stigma around problematic AOD use cause women such distress that it propels them to seek treatment in order to alleviate this distress. Earlier qualitative research which reported that women experience stigma in relation to their problematic use of AODs rather than their use of AOD service ${ }^{28}$ provides some support for this explanation. An alternative explanation is that this effect could have been influenced by a sampling bias as potential female controls that experienced stigma may have been less likely to participate in the study than controls who had not experienced stigma. However, given this study's low refusal rate, it is unlikely that a sampling bias is responsible for this unexpected finding.

Findings from this study should be considered in the light 
of several limitations. First, the use of a case-control design precludes a temporal examination of the factors associated with treatment utilization and thus inferences about causality cannot be drawn. Related to this, while we were able to compare factors associated with utilization for men and women, our matched design rules out an examination of gender differences in the likelihood of AOD treatment use. Third, our rather crude conceptualisation of access prevented us from exploring whether there were differences between participants who had unsuccessfully attempted to access treatment and those who had never tried to access treatment. Fourth, our strict selection criteria may have truncated the variability of the sample and contributed to most predisposing variables not being associated with treatment utilization. In addition, as this study sample was limited to adults from disadvantaged communities in Cape Town, the extent to which findings from this study are representative of more rural or other urban regions in South Africa is questionable. As the Western Cape Province is well resourced in terms of health and social services, relative to the other provinces in South Africa ${ }^{25}$, it is possible that structural and population-level barriers are even more salient in other provinces. Finally, our study did not examine two categories of variables that are strongly predictive of women's rather than men's non use of treatment services in other contexts: 1) concerns relating to dependent children (including access to child care whilst attending treatment and concerns around child custody) and 2) histories of victimisation. ${ }^{10-12}$

These limitations highlight the need for further research on AOD treatment utilization among men and women in South Africa. Future research should include longitudinal prospective studies that track men and women with AOD problems over time and allow researchers to unpack the factors that precipitate AOD treatment utilization for each gender. These longitudinal studies will also allow researchers to differentiate between individuals who needed services and did not try to access them, those that attempted to access treatment and were unsuccessful, and those that successfully accessed treatment. Future studies should attempt to include a broader range of variables thought specifically to impact on women's use of treatment services. To address concerns about the external validity of findings, studies on factors associated with AOD treatment utilization in other parts of the country (particularly rural regions) and for other population subgroups (such as adolescents) are required. In addition, researchers should conduct experimental intervention studies that test whether reducing geographic access and affordability barriers and improving service awareness impact positively on AOD treatment utilization for men and women from disadvantaged communities.

\section{Conclusion}

Despite some limitations this study provides good evidence that women from disadvantaged communities in Cape Town do not have equal opportunities to access AOD treatment relative to their male counterparts; with women being more vulnerable to the effects of awareness, affordability and geographic access barriers than men. Taken together, these findings suggest the need for targeted interventions that address gendered barriers to treatment utilization. Various strategies can be used to improve women's use of AOD treatment. For service planners, new services should be placed in locations easily accessible by public transport and in communities with high service needs and poor service coverage. Second, outpatient mobile clinics offer a low cost and geographically accessible means of providing AOD services, particularly as these clinics have limited infrastructural costs and can be moved between and within communities. Third, as financial concerns often compound geographic access barriers service providers should consider providing prospective female clients from poor communities with transport services. Service providers can also reduce the competing demands on female clients' limited financial resources through linking female clients with poverty alleviation programs that offer tangible support (in the form of food, shelter or economic assistance). Finally, service providers should consider using community-based outreach workers to improve awareness of AOD treatment among women residing in disadvantaged communities. Through educating women about when, where and how to access services, outreach workers can positively impact on women's use of AOD treatment services.

\section{Acknowledgements}

This material is based on work supported financially by the National Research Foundation (NRF), the Open Society Foundation, the First Rand Foundation, and the Western Cape Department of Social Development. Any opinion, findings, conclusions or recommendations expressed are views of the authors and therefore the NRF does not accept any liability in regard thereto.

\section{References}

1. Herman AA, Stein DJ, Seedat S, Heeringa SG, Moomal H, Williams DR. The South African Stress and Health (SASH) study: 12-month and lifetime prevalence of common mental disorders. S Afr Med J 2009; 99: 339-344.

2. Parry CDH, Plüddemann A, Steyn K, Bradshaw D, Norman R, Laubsher R. Alcohol use in South Africa: Findings from the first demographic and health survey (1998). J Stud. Alcohol 2005; 66: 91-97.

3. Parry CDH, Plüddemann A, Louw A, Leggett T. The 3-metros study of drugs and crime in South Africa: Findings and policy implications. Am J Drug Alcohol Abuse 2004; 30: 167-185.

4. Plüddemann A, Parry C, Donson H, Sukhai A. Alcohol use and trauma in Cape Town, Durban, and Port Elizabeth, South Africa: 1999-2001. Inj Control Saf Promot 2004; 11: 265-267.

5. Myers B, Louw J, Fakier N. Alcohol and drug abuse: Removing structural barriers to treatment for historically disadvantaged communities in Cape Town. Int J Social Welfare 2008; 17: 156-165.

6. Myers B, Parry CDH. Access to substance abuse treatment services for Black South Africans: Findings from audits of specialist treatment facilities in Cape Town and Gauteng. South African Psychiatry Review 2005; 8:15-19.

7. Myers B, Parry CDH, Pluddemann, A. Indicators of Substance Abuse Treatment Demand in Cape Town, South Africa (1997-2001). Curationis 2004; 27: 27-31.

8. May PA, Brooke L, Gossage JP, Croxford J, Adnams C, Jones KL, Robinson L, Viljoen, D. Epidemiology of fetal alcohol syndrome in a South African community in the Western Cape province. Am J Public Health 2000; 90: 1905-1912. 
9. Sawyer KM, Wechsberg WM, Myers B. Cultural similarities and differences between a sample of Black/ African and Coloured women in South Africa: Convergence of risk related to substance use, sexual behaviour and violence. Women Health 2006; 43: 73-92.

10. Green CA, Polen MR, Dickinson DM, Lynch FL, Bennett MD. Gender differences in predictors of initiation, retention and completion in an HMO-based substance abuse treatment program. J Subst Abuse Treat 2002; 23: 285-295

11. Greenfield SF, Brooks AJ, Gordon SM, Green CA, Kropp F, McHugh RK, Lincoln M, Hien D, Miele GM. Substance abuse treatment entry, retention and outcome in women: A review of the literature. Drug Alcohol Depend 2007;86: 1-21.

12. Saum CA, Hiller ML, Leigey ME, Inciardi JA, Surratt HL. Predictors of substance abuse treatment entry for crime-involved, cocainedependent women. Drug Alcohol Depend 2007; 91: 253-259.

13. Andersen RM. Revisiting the behavioral model and access to medical care. Does it matter? J Health Soc. Behav 1995; 36: 1-10.

14. Zemore SE, Mulia N, Ye Y, Borges G, Greenfield TK. Gender, acculturation, and other barriers to alcohol treatment utilization among Latinos in three National Alcohol Surveys. J Subst Abuse Treat 2009; 36: 446-456.

15. Andersen RM, Davidson PL. Access to medical care: Measurement and trends. In Andersen RM, Rice TH, Kominski GF. (Eds.), Changing the US Health Care System: Key Issues in Health Services, Policy and Management (pp 13-40). San Francisco: Josey Bass, San Francisco, 1996

16. Sobell $L C$, Sobell MB, Toneatto T. Recovery from alcohol problems without treatment. In Heather N, Miller WR, Greenley J. (Eds.), Selfcontrol and the Addictive Behaviors (pp 1198-1242). New York: Maxwell Macmillan, 1992

17. Knight $K$, Simpson DD, Hiller ML. Screening and referral for substanceabuse treatment in the criminal justice system. In Leukefeld CG, Tims F, Farabee D (Eds.), Treatment of Drug Offenders: Policies and Issues (pp 259-272). New York: Springer, 2002.
18. American Psychiatric Association. Diagnostic and Statistical Manual of Mental Disorders DSM-IV-TR (4th ed. revised). Washington DC: American Psychiatric Association Press, 2001.

19. Miller WR, Tonigan JS. Assessing drinker's motivation to change: The Stages of Change, Readiness and Treatment Eagerness Scale (SOCRATES). Psychol Addict Behav. 1996; 10: 81-89.

20. Crum RM, Lillie-Blanton M, Anthony JC. Neighborhood environment and opportunity to use cocaine and other drugs in late childhood and early adolescence. Drug Alcohol Depend 1996; 43: 155-61.

21. Meyers RJ, Miller WR, Smith JE, Tonigan JS. A randomized controlled trial of two interventions for engaging treatment refusing drug users through concerned significant others. J Consult Clin Psychol 2002; 70: 1182-1185.

22. Joe GW, Broome KM, Rowan-Szal GA, Simpson DD. Measuring patient attributes and engagement in treatment. J Subst Abuse Treat 2002; 22: 183-196

23. Ross MW, Williams ML, Timpson SA, Amos C, Bowen A. Stigma Consciousness of Drug Use and Sexuality in Male Commercial Sex Workers. WHO Centre for Health Promotion and Prevention Research, University of Texas, Houston, 2005.

24. Hatton DC. Homeless women's access to health services: a study of social networks and managed care in the US. Women \& Health 2001; 33: 149-162

25. Statistics South Africa Causes of Death, 2002. Pretoria: Statistics South Africa, 2003.

26. Tolhurst R, Nyonator FK. Looking within the household: Gender roles and responses to malaria in Ghana. Trans $R$ Soc Trop Med Hyg 2006; 100: 321-326.

27. Beardsley K, Wish ED, Fitzelle DB, O'Grady K, Arria AM. Distance traveled to outpatient drug treatment and client retention. J Subst Abuse Treat 2003; 25: 279-285

28. Myers B, Fakier N, Louw J. Stigma, treatment beliefs and substance abuse treatment use among historically disadvantaged communities. African Journal of Psychiatry 2009; 12: 218-222.

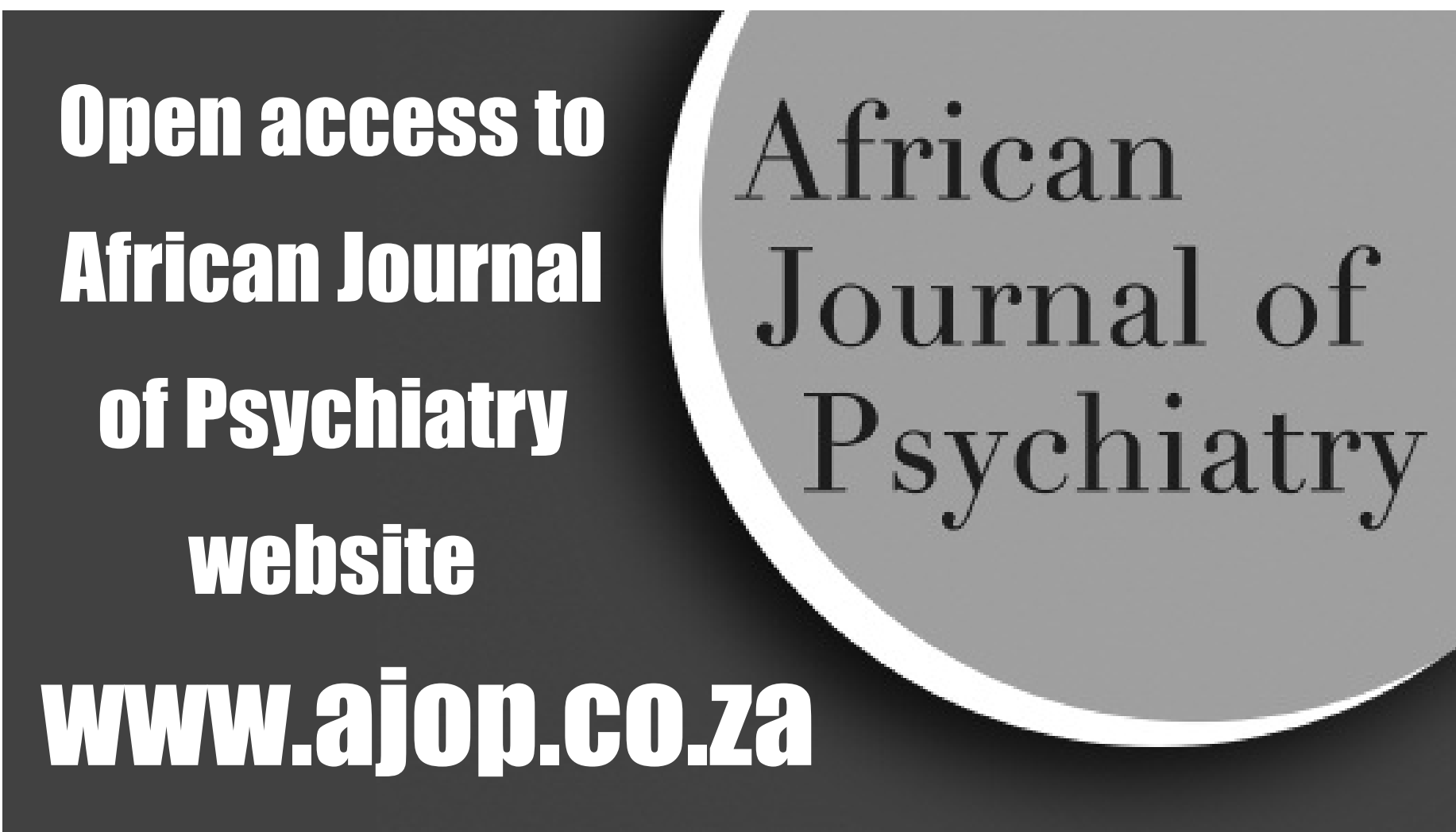

